\title{
TÁCTICAS EN MEATO-TRAYECTO INTRAMURAL
}

\author{
Carlos Rioja Sanz ${ }^{1}$ y José Vicente Rodríguez ${ }^{2}$ \\ ${ }^{1}$ Servicio de Urología. Hospital Universitario M iguel Servet Zaragoza. \\ ${ }^{2}$ Fundación Puigvert Barcelona. Barcelona. España.
}

\section{ÍN DICE/ RESUMEN}

1. Tácticas en desinserción ureteral.

C. Rioja Sanz y J. Vicente Rodríguez.

2. Tácticas en ureterocele del adulto.

J. Vicente Rodríguez.

3. Tácticas en tumor en / sobre meato-trayecto intramural del ureter ¿qué táctica seguir?.

J. Vicente Rodríguez.

Palabras dave: Tácticas en meato. Desinserción ureteral. Ureterocele. Trayecto intramural.
Carlos Rioja Sanz

Servicio de Urología Hospital Universitario M iguel Servet

Pso. Isabel la Católica, 1-3 50009 -Zaragoza (España)

\section{TÁCTICAS EN DESINSERCIÓN URETERAL}

C. Rioja Sanz y J. Vicente Rodríguez.

La desinserción ureteral endoscópica facilita enormemente y acorta el tiempo quirúrgico de una nefroureterectomía en el tratamiento de un tumor de urotelio superior. Esta técnica evita la incisión pararrectal en la cirugía abierta, pudiéndose extraer el riñón y uréter a tra vés de la incisión de lumbotomía, y facilita igualmente su exéresis por vía laparoscópica.

En nuestra experiencia la desinserción se realiza más fácilmente con el asa de Collins ya que su forma facilita la incisión perimeatica. La desinserción se realiza a golpes intermitentes con energía de corte, breves y continuados, siempre visualizando el tejido a cortar y coagulando minuciosamente los vasos que van apareciendo La colocación de un catéter ureteral presenta varias ventajas: minimizaría, en teoría, la salida de orina de esa unidad al retroperitoneo al desinsertar el uréter y sobre todo nos facilita los gestos quirúrgicos para avanzar en la desinserción. Esta es especialmente más laboriosa en la porción posterior del uréter, en su entrada en el trígono, con gran riqueza de fibras musculares que forman estas estructuras y la vaina de Waldeyer. El catéter nos facilita la identificación anatómica del uréter y suaves movimientos del mismo, cambian su dirección y nos facilita la desinserción en los 360 을 hasta llegar a apreciar la completa liberación del uréter viendo grasa perivesical alrededor del mismo, quedando "suspendido" en la grasa embebida de suero de irrigación. 
Un punto conflictivo es el momento de la desinserción profunda en la porción lateral externa del uréter al existir vasos del pedículo inferior vesical e incluso llegar a las proximidades de los vasos uterinos en la mujer. En este punto es importante no realizar cortes a ciegas con el asa y es aconsejable realizar despegamientos del tejido con el asa sin usar energía eléctrica, simplemente empujando alrededor del uréter, quedando expuestos puentes musculares y vasos. La hidrodisección que produce el líquido de irrigación no solo no debe ser evitada sino que facilita enormemente la cirugía. Al finalizar la desinserción es importante re-explorar la vejiga vacía, sin presión pues pueden aparecer puntos hemorrágicos que no se apreciaban durante los gestos quirúrgicos.

Es importante al continuar la cirugía por vía abierta o laparoscópica proceder precozmente a la ligadura del uréter para evitar salida de orina y células al retroperitoneo.

\section{TÁCTICAS ENDOSCÓPICAS EN LA DESINSER- CIÓN URETERAL}

J.Vicente Rodríguez.

La nefroureterectomía por tumores del aparato urinario superior, clásicamente se realiza mediante dos incisiones o una lumbar prolongada. Para simplificar esta técnica, conservando su radicalidad oncológica, la cirugía endoscópica permite realizar la extracción o desinserción ureteral y reducir a una corta incisión lumbar / tiempo quirúrgico la nefroureterectomía clásica.
Hay dos series comparativas entre la extracción y desinserción ureteral endoscópicas: una sumatoria de P. Laguna (1) : 107 versus 129 casos (en los que se incluye nuestra experiencia (2) y otra actualizada de Ubrig y cols. (3): 16 c. de extracción versus 18 c. de desinserción. Sus características se resumen en la Tabla I.

Las diferencias entre ambas técnicas no son importantes, aunque parece que la extracción comporta mayor índice de complicaciones y la desinserción, mayor número de recidivas tumorales (vesicales y en área resecada)

N osotros, hemos realizado siempre la desinserción siguiendo la técnica de M cDonals (1952) y que se esquematiza en la Figura 1.

La TÁCTICA quirúrgica consta de tres fases secuenciales:

1a fase: Inyección previa de indigo de carmín (localización del meato y "trayecto azul" del uréter intramural). Resección transuretral trigonal (lateral/ posterior a meato), desarbolando las fibras murales que fijan el trayecto uretral intramural.

2a fase: El meato/trayecto uretral quedan como un pezón o "trompa de elefante" aislados; se sigue resecando la parte emergente vesical y a coagular la boca ureteral resecada (evitar la posible implantación celular).

3a fase: finalización de la desinserción con el asa: empuje cefálico o cortes tipo Morse y con el chorro

TABLA I.

\begin{tabular}{|llccccc|}
\hline SERIES & A & B & \multicolumn{2}{c}{ Tumor en área RTU } & A & B \\
& Recidiva Tm.V. $\%$ & A & B & Complicaciones \% \\
\hline Laguna (1) & 19,3 & 24 & 0 & 3,1 & 10,2 & 2,7 \\
\hline (Palou y cols.) & -- & 27,3 & -- & 0 & -- & 3,3 \\
\hline Ubrig (3) & 16,6 & 35 & 0 & 0 & 0,06 & 0,05 \\
\hline
\end{tabular}

$\mathrm{A}=$ Extracción uret/ end

$B$ =Desinserción uret/ endos 


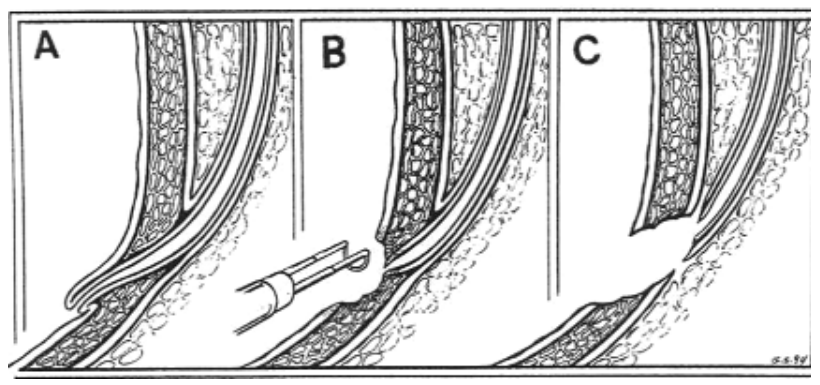

FIG URA 1.

irrigador creando un estravasado que facilitará (junto a la señalización por coagulación previa del final del uréter) la tracción del uréter desde la herida lumbar.

Esta técnica la desaconsejamos en tumores del uréter distal (por debajo del cruce de iliacos) dado que aumenta el riesgo de diseminación celular y no nos permitirá realizar la linfodenectomía regional de estadiaje.

En nuestra experiencia: 31 casos publicados (2) (en la última cuantificación eran 74 casos) y 32 casos previos a nefroureterectomía laparoscópica (66 casos de 2 - 2001 a 11 - 2004), no hemos detectado ningún caso de tumor en el área trigonal resecado; solamente hay descritos dos casos por Hetherington (Brit J. 1986), un caso por Jones y Morey (Brit J. 1993) y un caso por Arango y cols. (J.Urol. 1997). Sin despreciar estos cuatro casos publicados, consideramos que el riesgo de implantación/ nuevo tumor en el área resecada es clínicamente irrelevante.

\section{BIBUOGRAFÍA RECOMENDADA}

1. LAGUNA, P.; DE LA ROSETTE, J.: "The endoscopie approach to the distal ureter in nephroureterectomy for upper urinary tract tumor". J. Urol., 166: 2017, 2001.

2. PALOU, J.; CAPARRÓS, J.; ORSOLA, A. y cols.: "Transurethral resection of the intramural ureter as the first step of nephroureterectomy". J. Urol., 154: 43, 1995.

3. UBRIG, B.; BORNING, M.; WALDNER, M. y cols.: "Transurethral approach to the dital ureter in nephroureterectomy: transurethral extraction us "pluck" technique with long term follow-up". Eur. Urol., 46: 741, 2004.

\section{TÁCTICAS ENDOUROLÓGICAS EN URETE- ROCELE DEL ADULTO.}

J. Vicente Rodríguez.

La incidencia del ureterocele es baja (entre 1 $x 500$ a 1 x 4000) y más frecuente en la infancia que en adultos; en un rastreo bibliográfico entre 1999 y 2004 , de 26 artículos sobre cirugía endoscópica en ureterocele, sólo seis de ellos eran sobre adultos.

La mayoría de ellos son un hallazgo radiológico, pero un porcentaje de ellos se acompañan de dolor lumbar y/ 0 infecciones de repetición 0 más frecuentemente con cálculo en su interior.

Las indicaciones de intervención terapéutica se limitan a : urecele sintomático (sólo el 14 \% en nuestra experiencia inicial) y/o ureterocele habitado por cálculo (cuya expulsión es imposible).

La cirugía endoscópica es la más simple y atractiva a pesar del riesgo de reflujo vesico-uretral postquirúrgico. La punción transuretral del ureterocele es una solución transitoria o asociada a heminefrectomía (Husmann J.Urol. 1999).

La resección de la cúpula fue abandonada hace años por la alta incidencia de reflujo postoperatorio.

La incisión endoscópica es la más realizada:

Arciforme (1) que realizamos desde 19730 bien horizontal (2) que de forma similar se realiza en la actualidad; la incisión puede realizarse con electrodo de corte (1) (2) o bien con láser N d Yag (Gupta Int.Urol.Nephrol. 2001) o con láser Holmium ( Lieb J.Endourol. 2003).

N osotros desde la década de los 70 realizamos incisión en "boca sonriente", que representamos esquemáticamente en la Figura 2.

La TÁCTICA quirúrgica consta de tres fases secuenciales:

1a fase: Introducido el electrodo "bent" acodado a través del panendo, se espera a que el ureterocele esté en máxima replección y se marca con coagulación (uno central y dos laterales) en la unión vesico-ureterocele. 2a fase: se espera una nueva fase de replección y se realizan con el electrodo dos cortes rápidos entre los puntos laterales. 


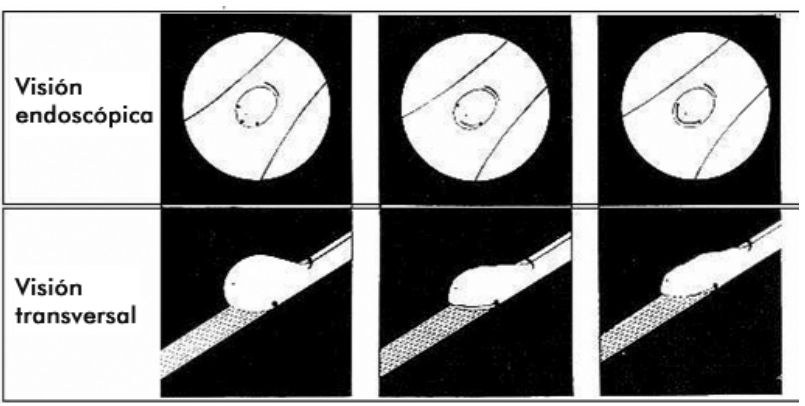

FIG URA 2 .

3a fase: con el propio electrodo se moviliza el/ los cálculos y se procede a su extracción o litotricia.

Con ella hemos conseguido en 43 casos de cálculo en ureterocele (3) el $93 \%$ de buenos resultados (que se repiten prácticamente en última revisión sobre 67 casos); la incidencia de reflujo postoperatorio es baja: $7 \%$, conseguida por la tonicidad uretral y por la oclusión que efectúa la "bisera" del ureterocele cuando aumenta la presión intravesical (fase de llenado).

\section{BIBUOGRAFÍA RECOMENDADA}

1. VICENTE, J.: "Incisión endoscópica en "boca sonriente" del ureterocele". Act. Urol. Esp., 3: 529, 1973.

2. CHTOURN, M.; SALLAMI, S. y cols.: "Ureterocele in adults complicated with calculi. Report of 20 cases". Prog. Urol., 12: 1213, 2002.

3. VICENTE, J.; LAGUNA, M.P. y cols.: "Endoscopic surgeri in ureteroceles's calculi in Urology 1992". Monduzzi Editore. 51, 1992.

\section{TUMOR EN / SOBRE MEATO - TRAYECTO INTRAMURAL DEL URÉTER. ¿QUÉ TÁCTICA SEGUIR ?}

J. Vicente Rodríguez

La táctica quirúrgica de elección, viene determinada por la localización del tumor trigonal (en nuestra experiencia el $11 \%$ ). Podemos encontrarnos en tres situaciones:

1. Tumor próximo al meato ureteral pero identificable a veces debajo de franjas tumorales, desplazables con el chorro irrigador. En estos casos actua remos siguiendo la técnica "resolutiva" de resección, predominando el criterio de radicalidad, al del respeto del meato.
En algunos casos, los cortes profundos ( 20 - 3을 corte en profundidad) engloba el trayecto intramural, creando un "neomeato" por encima del original; esta circunstancia no tiene significado clínico.

A sí como la resección debe seguir prioritariamente los criterios oncológicos, la electrocoagulación en zona meática / perimeática, debe ser extremadamente cuidadosa con el fin de evitar la estenosis secundaria.

2. Tumor ocultando el meato ureteral:

Inyección endovenosa de índigo de carmín para facilitar la localización del meato durante la RTU; ésta se realiza igual a la del Tm vesical de otra localización vesical. En el segundo / tercer corte de profundidad, el meato ureteral emerge como un pezón o pequeña "trompa de elefante". Es conveniente realizar un corte preciso que seccione la parte más prominente y enviarlo por separado para su estudio patológico.

Lógicamente en estos casos debería quedar meato de reflujo vesico-ureteral. En nuestra experiencia el reflujo post RTU de Tm . trigonal (66 casos) fue del 4,5 \% y sin embargo la incidencia de Tumores del Aparato U rinario Superior (TUS) (1529 casos) fue del 2,6\%. La elevada relación entre reflujo y TUS ( $40 \%$ en nuestros casos de TUS tratados endoscópicamente), debe valorarse como estudio en casos seleccionados y contando con la multifocalidad tumoral.

3. Durante la RTU del Tumor Trigonal, franjas tumorales afloran por el meato ureteral. Tenemos dos opciones: realizar ureteroscopia o continuar con la resección del trayecto ureteral intramural y realizar ureteroscopia diferida. Esta técnica es difícil dado que la RTU debe ser de todo el trayecto intramural pero sin provocar la desinserción ureteral.

En nuestra experiencia con esta técnica en 19 pacientes seguidos a media de 57 meses, los tumores de uréter terminal se comportan como cualquier TUS, en relación a las recurrencias: 42,1 \% (la mitad por encima del área resecada) pero hemos conseguido preservar la unidad renal en el $89,5 \%$ de los casos.

\section{BIBUOGRAFÍA RECOMENDADA}

1. VICENTE, J.; CHECHILE, G.; PALOU, J.: "Tumores Vesicales Superficiales". Ed. Acción Médica, Cap. Tratamiento endoscópico . J. Vicente. Pp.: 121-145. 2002.

2. PALOU, J.; SALVADOR, J.; VICENTE, J.: “Treatment of superficial transitional cell carcinoma in the intramural ureter. What to do?”. J. Urol., 163 :744, 2000. 